\title{
Relation between Quality of Nursing Work Life and Organizational Commitment
}

\author{
Mohmmed Ali Essa ${ }^{1}$, Sahar Ahmed Abood ${ }^{2}$, Mona Thabet ${ }^{3}$
}

1. B.Sc. Nursing,

2. Professor of Nursing Administration, Faculty of Nursing, Minia University,

3. Lecturer of Nursing Administration, Faculty of Nursing, Minia University

\begin{abstract}
Background: Nurses spend several hours a day in work environment; thus, quality of work life and organizational commitment are two important components for the staff, and dissatisfaction of these issues affects their other roles at home and community. The Work Life balance must be maintained effectively to ensure that all employees are working at their peak potential and free from stress. Aim: To assess the relation between quality of Nursing work life and organizational commitment. Research design: A descriptive cross- sectional research design. Subjects: A representative sample 30\% of total staff nurses $(\mathrm{N}=193)$. Setting: Chest Diseases Hospital, at Kuwait. Tools of data collection: included two tools; first tool Brook's Quality of Nursing Work Life Survey; second the Organizational Commitment of the Staff Nurses Questionnaire. Results: More than half of staff nurses (57.0\%) had the moderate level to the total quality of work life. Most staff nurses $(86.5 \%)$ had a moderate level of total organizational commitment. There were positive fair association between total organizational commitment of the staff nurses and their work life, work design, work context, work world, and total quality of nursing work life. Also, there were positive association between total quality of nursing work life of staff nurses and their affective, continuance and normative commitment. Conclusion: The findings of this study revealed that quality of nursing work life and organizational commitment were positively correlated. Recommendation: Increase nurses' satisfaction through competitive salaries, encourage the teamwork spirit and conduct periodical meetings to discuss their problems.
\end{abstract}

Keywords: Nursing, Organizational Commitment, Quality, Relation, Work Life.

\section{Introduction}

The goal of the health care system is to provide the physical, psychological, and social health for the people, and at the same time create an environment in which the health staff can deliver higher quality and more effective services. Moreover, nurses spend several hours a day in the work environment; thus, quality of work life and organizational commitment are two important components for nursing staff, and dissatisfaction of these issues affects their other roles at home and community (Hashempour, et al., 2018).

Quality of work life (QWL) is a subjective phenomenon that is impacted by personal perceptions and feelings. It refers to attitude towards the job and general satisfaction with work life and feelings of being valued and respected within the organization. Positive working environment and fulfillment of staff needs will lead to retain the current employees and improve the performance of the organization and organizational commitment. Therefore, the organizations should realize "what is required" to retain qualified nurses and to create and maintain suitable working environment that supports competent performance of nursing care (Pio \& Tampi, 2018).

Also, it is necessary to consider not only the diverse and complicated dimensions that create individual, group, and organizational needs and desires; but also individual and group differences in terms of high-quality working conditions, when dealing with keeping good employees. Thus, organization should have program to improve the quality of work life program which include any improvement in the organizational culture that support the growth and development of employees in the organization (Ong, et al., 2019).

Subsequently, the nurses' dissatisfaction with their own work life can cause problems such as job dissatisfaction, emotional exhaustion, burnout, job turnover, and poor commitment to the organization. These factors would in turn affect the quality of care provided by nurses. Also, the organization's success in achieving its goal depends on the quality of human resources. Therefore, attention should be paid to the nurses' physical and emotional needs. The quality of nursing work life (QNWL) reflects the extent of nurse's satisfaction with important personal needs as growth and safety. Thus, the manager must become less of a supervisor and more of a coach or helper available to provide assistance and support when the need arises (Kowitlawkul, et al., 2019).

Regular assessment of QWL can potentially provide organizations with important information about the welfare of their employees, such as job satisfaction, general well-being, work-related stress and the homework interface. Focusing on improving QWL to increase the happiness and satisfaction of employees can result in many advantages for the employee, organization and consumers. These include improving quality of care, increasing the productivity of both the individual and the organization, and strengthening organizational commitment, (Liu et al., 2018).

Organizational commitment is one of the basic concepts that describe the relationship between an employee and an organization. Organizational commitment is an important occupational and organizational attitude that has drawn researchers' interests in organizational behavior courses in recent years because it is an important variable in understanding employee's behavior. Organizational commitment can be defined simply as loyalties to the values and goals of the organization, sense of belonging, dependency, and moral obligation to stay in the organization (Ramdhani, et al., 2017).

Also, Organizational commitment is defined as loyalties to the values and goals of the organization, sense of belonging, dependency, and moral commitment to remain in their organization. The organizational commitment is influenced by work life quality. When 
the employees are satisfied with their work life, they will be more obligated and stay in their organization; in which the individual's work life quality had a direct effect on organizational commitment (Osemeke, 2016).

Engagement and retention of sufficient and wellcommitted nurses are needed for providing safe and effective health care. Leaders should always take into consideration cultural differences, job satisfaction and commitment of staff nurse while framing policies. Nursing leaders must be equipped with the information needed to contribution in making a workplace attract the new nurses, retain the nurses they already has, and searching for ways to re-engineer the healthcare system particularly by providing supportive environment to staff, improve quality of work life, to have good practice and commitment from their staff members (Akter, et al., 2018).

\section{Significance of the Study}

Absence of (QWL) leads to dissatisfaction in job, increases absenteeism, lack of motivation and morale, increased accident rates, lack of productivity, lack of organizational commitment, etc. Further it helps in attracting and retaining efficient and effective employees for right job profile, which in turn leads to employees and organizations' success. The Work Life balance must be maintained effectively to ensure that all employees are working at their peak potential and free from stress (Beloor, et al., 2017).

Moreover, preliminary evidence suggests that the improvement of QNWL is prerequisite to increased productivity in hospitals. Thus, the QNWL is in need of scholarly investigation. Moradi et al., (2014) reported from their study results that $60 \%$ of nurses reported that they had moderate level of quality of working life while $37.1 \%$ and $2 \%$ had undesirable and good quality of working life, respectively. Also, Lateef, et al., (2021) present in their study about the "Relationship between Quality of Work Life, Psycho-Social Safety Climate and Nursing Staff Work Engagement and Organizational Commitment" and concluded that there was a negative but not significant correlation between quality of work life and organizational commitment. So, the purpose of this article is to explore the relation between quality of Nursing work life and organizational commitment among staff nurses.

\section{Aim of the Study}

The aim of the current study was to assess the relation between quality of Nursing work life and organizational commitment among staff nurses.

\section{Research Questions}

1. What are the staff nurses' levels about quality of Nursing work life?

2. What are the levels of staff nurses about organizational commitment?

3. Is there a relation between quality of Nursing work life and organizational commitment?

\section{Subject and Methods \\ Research Design}

Descriptive cross-sectional research design was used to achieve the aim of the current study

\section{Setting}

The study was conducted in Chest Diseases Hospital, at El-sabah region, Kuwait city, in Kuwait. The hospital consists from 5 building: the main building which include three floors, the outpatients building which include three floors, the pulmonary rehabilitation building which include three floors, the radiology building which include three floors, and the medical records building which include two floors. The hospital beds capacity are 322 .

\section{Subjects}

Study subject was included a representative sample $30 \%$ of total staff nurses who working at Chest Diseases Hospital, at Kuwait. The study subjects were selected randomly from all units and departments $(\mathrm{N}=193)$

\section{Data Collection Tools}

Data was collected by using two tools which are self-administered tools and include the following:

Tool (I) it was included two parts as follows:

Part I: Personal data sheet which included information about staff nurses such as: age, gender, nationality, education level, years of experience in nursing, years of experience in current department, and unit.

\section{Part II: Brook's Quality of Nursing Work Life Survey:}

This tool was developed by Brooks and Anderson (2005) to assess the Quality of nursing work life. The tool contained 42 statements about nursing work life, divided into four dimensions as: Work Life-Home life (seven items), Work Design (10 items), Work context (20 items), and Work World (five items). The response for each item was measured on a five-point scale: "strongly agree=5," "agree=4," "uncertain=3," "disagree=2," and "strongly disagree=1." The score ranged from (42) to (210) and divided as (42 to 98) indicated low QWL, from (99 to 154) indicated moderate QWL level, from (155-210) indicated high QWL.

\section{Tool II: The Organizational Commitment of the Staff Nurses Questionnaire:}

This tool developed by Meyer et al. (1993) and was adopted by the researcher. It included 18 items divided to three factors of organizational commitment (affective, continuance, and normative). Each factor includes 6 items and was measured using five-point Likert scale $(1=$ strongly disagree, $2=$ disagree $3=$ neutral, $4=$ agree, $5=$ strongly agree); and there were Four items negatively worded and scoring were reversed. The scoring system was ranged from 18 to 90, and divided as follows; from (18 to 42) indicated low organizational commitment level, from (43 to 66) indicated moderate organizational commitment level, and from (67 to 90) indicated high organizational commitment level.

\section{Validity of the tools:}

Tools were tested for the content validity by a jury of (5) experts in the field of Nursing Administration and no necessary modifications were done. The jury composed of two Assistant Professors from Faculty of Nursing, Minia University; and three Professors from Chest Diseases Hospital, at Kuwait. Each of the expert panel was asked to examine the instruments for content coverage, clarity, wording, length, format, and overall appearance. No necessary modification was done from jury panel.

\section{Reliability of the tools}

Reliability of the tools was performed to confirm consistency of tool. The internal consistency measured to identify the extent to which the items of the tools measured 
the same concept and correlate with each other by Cronbach's alpha test that revealed good internal reliability for the tools; and it was (0.867) for Brook's Quality of Nursing Work Life Survey, and was (0.833) for Organizational Commitment of the Staff Nurses Questionnaire

\section{Pilot Study}

A pilot study was conducted on $10 \%$ (19 nurse's staff) of participants to ascertain the clarity, comprehensiveness, and applicability of the tools as well as to estimate the appropriate time required to fill the questionnaire. Based on pilot study there was no modification done, and it was added to final results.

\section{Data Collection Procedure}

- An official letter was granted from the Nursing Faculty Dean at Minia University, ministry of Health - Kuwait and the director of Chest Diseases Hospital, at Kuwait.

- Written approvals were obtained from Director of Chest Diseases Hospital, at Kuwait after explaining the purpose of the study.

- The tools were distributed to all the participants after explaining the purpose and process of data collection. Tools were directly administered and supervised by the researcher with the assistance of head nurse for each department.

- The researcher distributed the study self-administered tools to the participants through morning and evening shift during the working days.

- Participants were given from 20 minute to 30 minutes to answer the tools. They were allowed to discuss with researcher any item that needs more clarification.

- The data collection was performed from staff nurses of Chest Diseases Hospital, at Kuwait during the period of 6 months from the beginning of December 2018 to the beginning June 2019

\section{Administrative design}

A written initial approval was obtained from the Research Ethics Committee of the Faculty of Nursing, Minia University. An official letter was granted from Faculty Dean, Ministry Of Health - Kuwait and director of Chest Diseases Hospital, at Kuwait.

\section{Ethical Consideration}

The participants were informed that their participation in the study was completely voluntary and there was no harm if they do not participate in the study. Informed consent was obtained from staff nurses after explaining the nature and benefits of the study. Each tool was coded, and participants' name was not appearing on the sheets for the purpose of anonymity and confidentiality.

\section{Data statistical analysis}

Data entry was done using compatible personal computer. Statistical analysis done by using statistical package of social science (SPSS, IBM) version 25 and excel for figures. The content of each tool was analyzed, categorized, and then coded. Data were presented using descriptive statistics in the form of frequencies and percentages for qualitative variables and; means and standard deviations for quantitative variables.

Statistical significance used at $\mathrm{P}$ value $<0.05$. Chisquare test was used to detect the relation between demographic data of nursing staff and their quality of nursing work life and their organizational commitment.

Correlation is used to test the nature and strength of relation between two quantitative variables. The spearman correlation co-efficient (RHO) is expressed as the Pearson coefficient. The sign of the co-efficient indicates the nature of relation (positive/ negative) while the value indicates the strength of relation as follows: Weak correlation for Rho less than 0.25 , fair correlation for rho of value between $0.25-0.499$ and moderate correlation for values between $0.50-0.74$ and strong correlation for values more than 0.74 .

Results

Table (1): Distribution of the staff nurses according to their personal data $(n=193)$

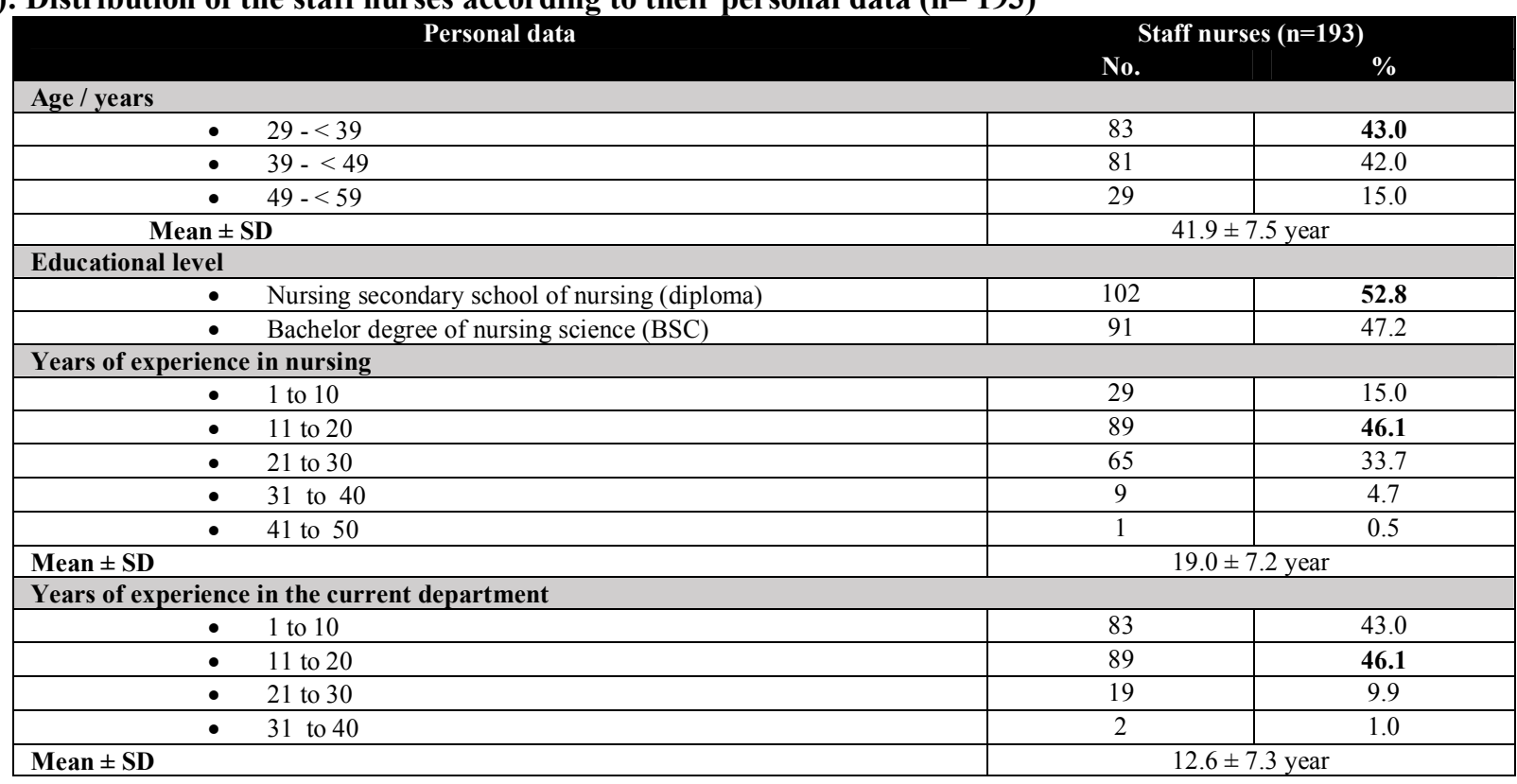


Minia Scientific Nursing Journal (Print - ISSN 2537-012X) (Online - ISSN 2785-9797) Vol. (10) No. (1) December 2021

Table (1): presents that (43.0\%) of staff nurse's age are between $29-<39$ with mean age $41.9 \pm 7.5$ years; there are (52.8\%) of them have Nursing secondary school of nursing (diploma), and there are (46.1\%) of them have from 11 to 20 years of experience in the nursing field and current department

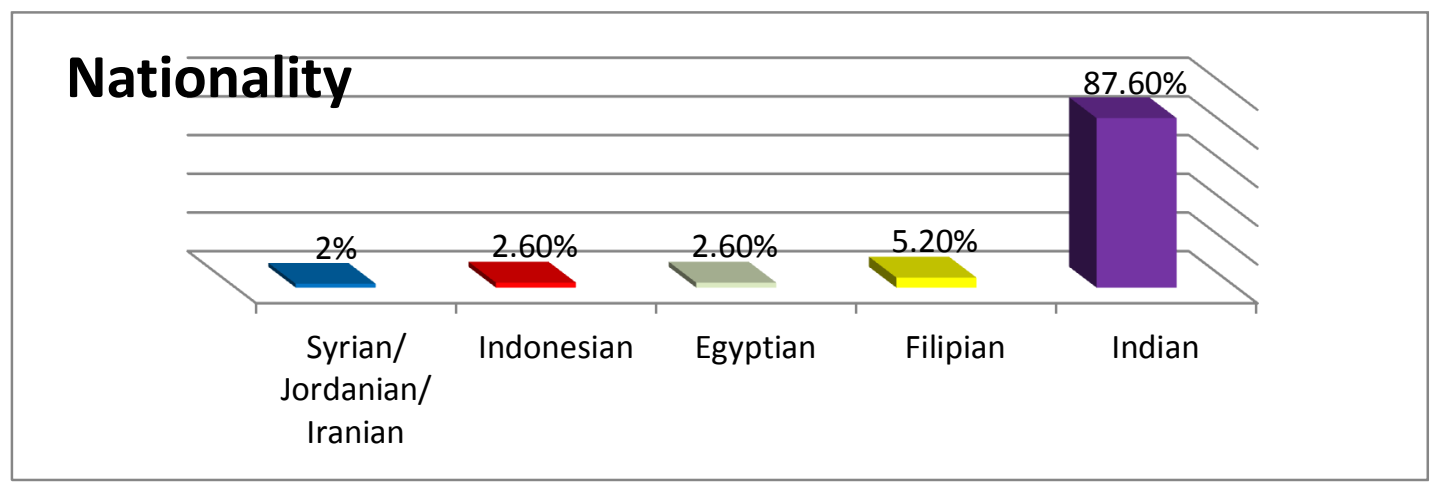

Figure (1): Distribution of the staff nurses according to their nationality $(n=193)$.

Figure (1) shows that the (87.6\%) of the staff nurses nationality are Indian and the minority of them are Filipina, Egyptian, Indonesian, Syrian, Jordanian, and Iranian (5.2\%, 2.6\%, 2.6\%, and 2.0\% respectively).

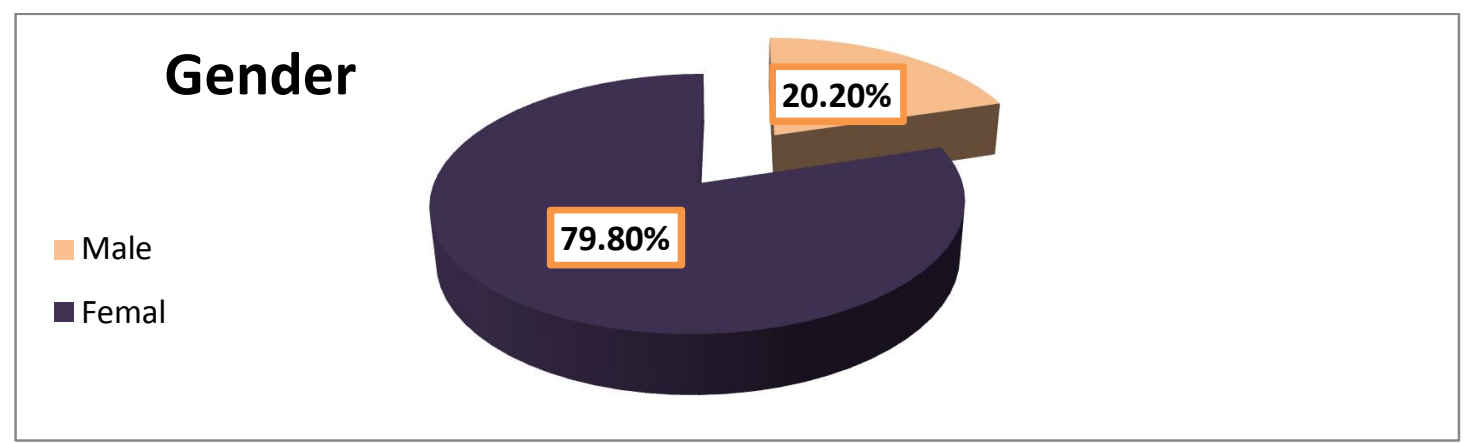

Figure (2): Distribution of the staff nurses according to their gender $(n=193)$

Figure (2) shows that (79.8\%) of the staff nurses are female and only (20.2\%) of them are male

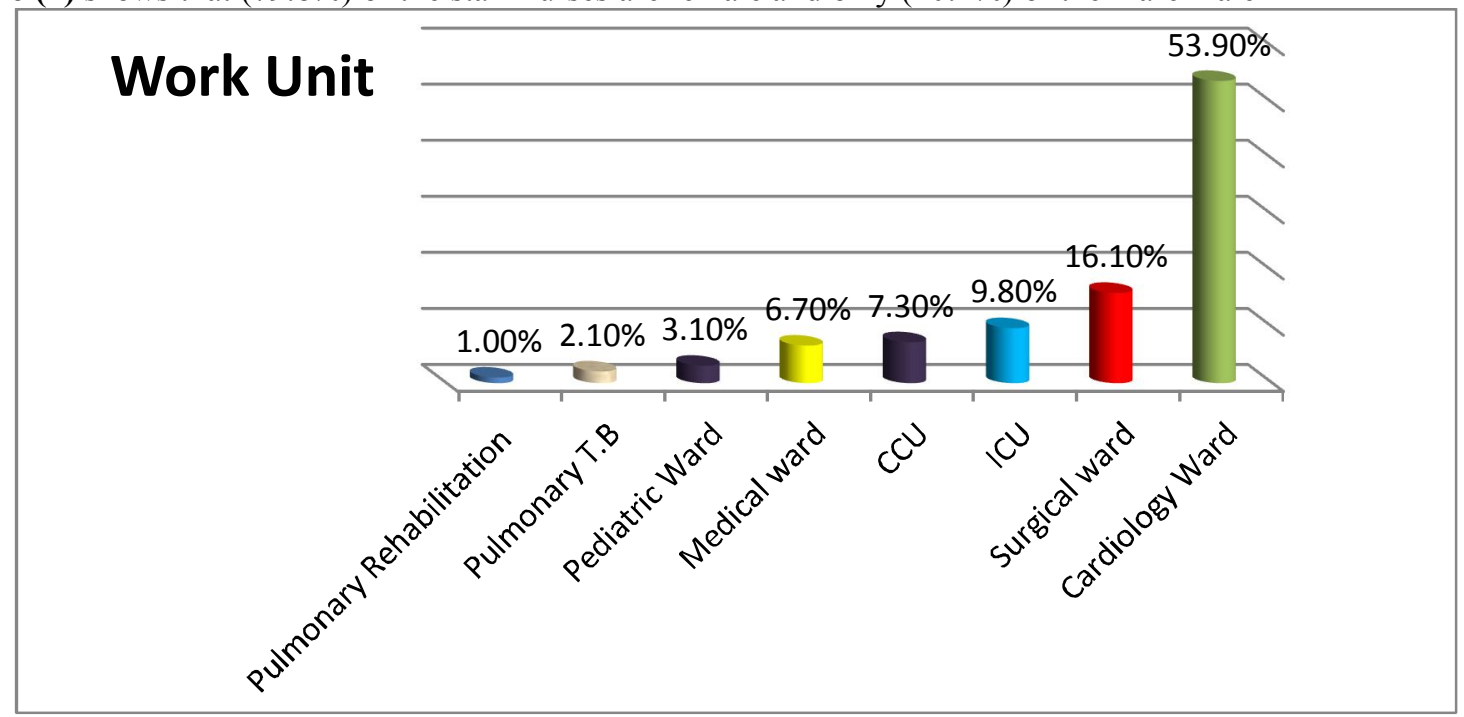

Figure (3): Distribution of the staff nurses according to their work unit $(n=193)$

Figure (3) displays that the $(53.9 \%)$ of the staff nurses work in the cardiology ward and the minority of them work in pulmonary rehabilitation $(1.0 \%)$.

Table (2): Distribution of Staff Nurses Level of quality of work life and its domains (n= 193)

\begin{tabular}{|c|c|c|c|c|c|c|}
\hline \multirow{3}{*}{ Quality of Work Life Dimensions } & \multicolumn{6}{|c|}{ Staff Nurses Level of quality of work life $(n=193)$} \\
\hline & \multicolumn{2}{|c|}{ Low } & \multicolumn{2}{|c|}{ Moderate } & \multicolumn{2}{|c|}{ High } \\
\hline & No & $\%$ & No & $\%$ & No & $\%$ \\
\hline - Work life & 0 & 0.0 & 81 & 42.0 & 112 & 58.0 \\
\hline - Work design & 0 & 0.0 & 157 & 81.3 & 36 & 18.7 \\
\hline - Work context & & & & & & \\
\hline * Management and supervision & 2 & 1.0 & 34 & 17.6 & 157 & 81.3 \\
\hline
\end{tabular}


Minia Scientific Nursing Journal (Print - ISSN 2537-012X) (Online - ISSN 2785-9797) Vol. (10) No. (1) December 2021

\begin{tabular}{|c|c|c|c|c|c|c|}
\hline \multirow{3}{*}{ Quality of Work Life Dimensions } & \multicolumn{6}{|c|}{ Staff Nurses Level of quality of work life $(n=193)$} \\
\hline & \multicolumn{2}{|c|}{ Low } & \multicolumn{2}{|c|}{ Moderate } & \multicolumn{2}{|c|}{ High } \\
\hline & No & $\%$ & No & $\%$ & No & $\%$ \\
\hline Co-workers & 0 & 0.0 & 7 & 3.6 & 186 & 96.4 \\
\hline * Development opportunities & 3 & 1.6 & 35 & 18.1 & 155 & 80.3 \\
\hline * Work environment & 0 & 0.0 & 30 & 15.5 & 163 & 84.5 \\
\hline Total Work context & 0 & 0.0 & 31 & 16.1 & 162 & 83.9 \\
\hline - Work world & 1 & 0.5 & 123 & 63.7 & 69 & 35.8 \\
\hline Total quality of work life & 0 & 0.0 & 110 & $\mathbf{5 7 . 0}$ & 83 & 43.0 \\
\hline
\end{tabular}

Table (2): presents that (58.0\%) of staff nurses have high level to work life dimension; and there are $(81.3 \%)$ of the staff nurses have moderate level to work design dimension. Regarding work context, there are $(81.3 \%, 96.4 \%, 80.3 \%$, and $84.5 \%)$ of staff nurses have high level for all sub-dimensions as: Management and supervision, Co -workers, Development opportunities, and Work environment respectively; and for the total of work context dimension there are $(83.9 \%)$ of the staff nurses have high level.

Also, there are $(63.7 \%)$ of staff nurses have moderate level to work world dimension. Speaking about total score of quality of work life, there are $(57.0 \%)$ of staff nurses have moderate level to the total quality of work life; and (43.0\%) have high level to the total quality of work life.

Table (3): Distribution of Staff Nurses Level Organizational Commitment dimensions (n=193)

\begin{tabular}{|c|c|c|c|c|c|c|}
\hline \multirow{3}{*}{ Organizational Commitment Dimensions } & \multicolumn{6}{|c|}{ Staff Nurses Level Organizational Commitment $(n=193)$} \\
\hline & \multicolumn{2}{|c|}{ Low } & \multicolumn{2}{|c|}{ Moderate } & \multicolumn{2}{|c|}{ High } \\
\hline & No & $\%$ & No & $\%$ & No & $\%$ \\
\hline - Affective Commitment & 6 & 3.1 & 178 & 92.2 & 9 & 4.7 \\
\hline - Continuance Commitment & 9 & 4.7 & 137 & 71.0 & 47 & 24.4 \\
\hline - Normative Commitment & 11 & 5.7 & 135 & 69.9 & 47 & 24.4 \\
\hline Total Organizational Commitment & 0 & .0 & 167 & 86.5 & 26 & 13.5 \\
\hline
\end{tabular}

Table (3) presents that (92.2\%) of staff nurses have moderate level to affective commitment dimension, as well less than $(71.0 \% \& 69.9 \%)$ of them have moderate level to the continuance and normative commitment to the organization respectively. Concerning total organizational commitment, there are $(86.5 \%)$ of staff nurses have moderate level of total organizational commitment; while only $(13.5 \%)$ of them have low level of total organizational commitment.

Table (4): Correlations matrix between the quality of nursing work life of staff nurses' and their organizational commitment

\begin{tabular}{|c|c|c|c|c|c|c|c|c|c|}
\hline & & $\begin{array}{l}\text { Work } \\
\text { life }\end{array}$ & $\begin{array}{l}\text { Work } \\
\text { design }\end{array}$ & $\begin{array}{l}\text { Work } \\
\text { context }\end{array}$ & $\begin{array}{l}\text { Work } \\
\text { world }\end{array}$ & $\begin{array}{c}\text { Total } \\
\text { QNWL }\end{array}$ & $\begin{array}{c}\text { Affective } \\
\text { Commitm } \\
\text { ent }\end{array}$ & $\begin{array}{c}\text { Continuanc } \\
\mathrm{e} \\
\text { Commitme } \\
\mathrm{nt}\end{array}$ & $\begin{array}{c}\text { Normative } \\
\text { Commitme } \\
\text { nt }\end{array}$ \\
\hline \multirow[t]{2}{*}{ Work-Life } & $\mathrm{r}$ & & & & & & & & \\
\hline & $P$-value & & & & & & & & \\
\hline \multirow[t]{2}{*}{ Work design } & $\mathrm{r}$ & $209^{* *}$ & & & & & & & \\
\hline & $P$ - value & .004 & & & & & & & \\
\hline \multirow[t]{2}{*}{ Work context } & $\mathrm{r}$ & $.370^{* *}$ & $.433^{* *}$ & & & & & & \\
\hline & $P$-value & .0001 & .0001 & & & & & & \\
\hline \multirow[t]{2}{*}{ Work world } & $\mathrm{r}$ & $.344^{* *}$ & $.327^{* *}$ & $.444^{* *}$ & & & & & \\
\hline & $P$-value & .0001 & .0001 & .0001 & & & & & \\
\hline \multirow[t]{2}{*}{ Total QNWL } & $\mathrm{r}$ & $.567^{* *}$ & $.652^{* *}$ & $911^{* *}$ & $.652^{* *}$ & & & & \\
\hline & $P$-value & .0001 & .0001 & .0001 & .0001 & & & & \\
\hline \multirow[t]{2}{*}{ Affective Commitment } & $\mathrm{r}$ & $.142^{*}$ & .124 & .096 & $.229^{* *}$ & $.172^{*}$ & & & \\
\hline & $P$-value & .049 & .085 & .184 & .001 & .017 & & & \\
\hline \multirow[t]{2}{*}{ Continuance Commitment } & $\mathrm{r}$ & $.210^{* *}$ & $.352^{* *}$ & $.295^{* *}$ & $.245^{* *}$ & $.374^{* *}$ & $.297^{*}$ & & \\
\hline & $P$-value & .003 & .0001 & .0001 & .001 & .0001 & .0001 & & \\
\hline \multirow[t]{2}{*}{ Normative Commitment } & $\mathrm{r}$ & $.256^{* *}$ & $.390^{* *}$ & $.412^{* *}$ & $.297^{* *}$ & $.478 * *$ & $.284 * *$ & $.594^{* *}$ & \\
\hline & $P$-value & .0001 & .0001 & .0001 & .0001 & .0001 & .0001 & .0001 & \\
\hline \multirow{2}{*}{$\begin{array}{l}\text { Total organizational } \\
\text { commitment }\end{array}$} & $\mathrm{r}$ & $.265^{* * *}$ & $.389^{* *}$ & $.360^{* * *}$ & $.329^{* *}$ & $.454^{* * *}$ & $.605^{* * *}$ & $.865^{* *}$ & $.829^{* *}$ \\
\hline & $P$-value & .0001 & .0001 & .0001 & .0001 & .0001 & .0001 & .0001 & .0001 \\
\hline
\end{tabular}

Table (4) presents that there are positive associations between total organizational commitment of the nurse's staff and their work life, work design, work context, work world, and total quality of nursing work life $(\mathrm{r}=0.265, \mathrm{P}<0.0001 ; \mathrm{r}=0.389$, $\mathrm{P}<0.0001$; $\mathrm{r}=0.360, \mathrm{P}<0.0001 ; \mathrm{r}=0.329, \mathrm{P}<0.0001 ; \mathrm{r}=0.454, \mathrm{P}<0.0001$ respectively). Also, there are positive associations between total quality of nursing work life of staff nurses and their affective, continuance and normative commitment $(\mathrm{r}=0.172, \mathrm{P}<0.017 ; \mathrm{r}=0.374$, $\mathrm{P}<0.0001$; and $\mathrm{r}=0.478, \mathrm{P}<0.0001$ respectively).

\section{Discussion}

High quality of work life (QWL) is essential for organizations to achieve high performance and growth in profitability and to continue to attract and retain employees. QWL is a comprehensive, department- wide program designated to improve employee satisfaction, strengthening workplace learning and helping employees had better manage change and transition. Dissatisfaction with QWL is a problem, which affect almost all workers regardless of their position or status (Farokhzadian, et al., 2018).

In the current study regarding the personal data of the studied nurses, the current study revealed that more than one thirds of staff nurse's aged between $29-<39$ with mean age $42.0 \pm 7.5$ years, more than half of them had a nursing diploma, and near to half of them had experience in the nursing field and current department. 
According to the nationality of the studied nurses, the present study illustrated that the majority of the staff nurses nationality was Indian and the minority of them were Filipina, Egyptian, Indonesian, Syrian, Jordanian, and Iranian. The current result may be related to that Kuwait country had shortage in the nursing staff so they are hiring staff nurses from many other country.

Regarding the studied nurses' gender, the current study demonstrated that the more than three quarters of the staff nurses were female and one fifth of them were male. Regarding the units where the studied nurses work, the current study illustrated that the more than half of the staff nurses worked in the cardiology ward and a minority of them worked in surgical word, ICU, CCU, medical ward, pediatric ward, pulmonary T.B, and pulmonary rehabilitation.

Furthermore, the current study revealed about staff nurses level of quality of work life domains that more than half of staff nurses had a high level to work life dimension; and most of the staff nurses had a moderate level to work design dimension. Regarding work context sub-dimensions which namely; the Management and supervision, Co workers, Development opportunities, and work environment; it was noted that most of the staff nurses had a high level for all sub-dimensions. For the total of work context dimension the majority of the staff nurses had a high level. Also, the current study showed that two-thirds of staff nurses had a moderate level to work world dimension.

These results indicated that the staff nurses almost had from moderate to high level of satisfaction for all dimensions of quality of work life in nursing. Also, these results indicated that the studied sample had acceptable level of responses for their ability to balance their work with their family needs. These results may be due to the satisfaction of the staff nurses regarding their work environment and good relations in the work. Also, they receive a sufficient amount of assistance from support personnel, had the autonomy to make patient care decisions, and may had enough time to do their job well.

The result of current study showed that highest percent of staff nurses had high level of work life dimension; which differ with Akram and Awad (2020) who studied "The Quality of Work-life among Intensive Care Unit Nurses at Governmental Hospitals in Gaza Strip" and reported that the overall level of work-life domains was moderate.

Also, this result is not congruent with (Bayoumy, 2016) who studied "Relationship Between Quality of Work Life and Nurses' Professional Commitment in Intensive Care Units at Selected University Hospitals" and reported that, the nurse's response to the quality of work life subscales was from neutral to agreement level.

Furthermore, the study results displayed that most of the staff nurses had moderate level to work design dimension. This results is in agreement with Ali, et al., (2019) who had a study at Menoufia University Hospital at Shebin El-Kom, Menoufia Governorate, Egypt and assessed "the work design and its Relation to Productivity among Staff Nurses"; and revealed that the majority of studied staff nurses had moderate levels of work design characters

Regarding work context sub-dimensions and total score; the majority of the staff nurses had high level. This result have an agreement with (Morsy \& Sabra, 2015) who reported that the highest mean scores of quality of work life was related to work context dimension, which included sub dimensions as management and supervision, coworkers, development and opportunities, and work environment.

Speaking about total score of quality of work life; it was noted that more than half of staff nurses had the moderate level to the total quality of work life; and less than half of them had a high level to the total quality of work life. These results may be due to the moderate level of acceptance of staff nurses regarding their work. Staff nurses have satisfaction level that the quality of work life in their work environment is good and acceptable but it still need for more improvement; as they mentioned that rotating schedules negatively affect their life and it is important for a hospital to offer employees onsite daycare for elderly parents. Also, they reported that the workload is too heavy, and they need more support from administrative authority's personnel

This study findings come in the line with a study conducted in Tehran by Nayeri, et al. (2011) who studied " Quality of work life and productivity among Iranian nurses" and reported from their findings that QWL was at moderate level among participated nurses. Also this result is supported by Moradi, et al., (2014) who studied " Quality of Working Life of Nurses and its Related Factors" and reported that less than half of the studied nurses reported that they had moderate level of quality of working life.

But this result comes inconsistent with Elshahat, et al., (2019) who studied "Relationship between quality of work life and turnover intention among staff nurses" and reported that more than half of the studied sample had low quality of work life. Moreover, this study finding is inconsistence with a study conducted at Ain Shams University specialized hospital Shazly \& Fakhry, (2014) who mentioned that, nurses had low perception of the quality of work life. Also, this result is incongruence with Morsy and Sabra (2015) who pointed that more than two thirds of the nurses had low quality of work life. In addition Lee, et al., (2013) reported the same result.

Concerning staff nurses level for the dimensions of organizational commitment; it was observed from the current study finding that most of the staff nurses had moderate level to affective commitment dimension of the organizational commitment, less than three-quarters of them had moderate level to the continuance and normative commitment to the organization respectively.

These results indicated that the staff nurses at the study setting had moderate level of agreement regarding all dimensions of organizational commitment. These results may be due to the fear of staff nurses to leave their job and be unemployed; especially because they are from different countries and had different nationality; they also came to Kuwait in order to have a work and earn money, so they have a level of commitment to their organization. However the level of commitment was not in high level due to their unmet needs as more flexibility of hospital policies, have health insurance, and have good relations with other health care team. In addition the heavy workload, work stress and burdens of life have an impact on staff nurses level of their commitment.

These results have an agreement with Ali, et al., (2020) who had a study about "relation between Leadership Styles and Behaviors of Nurse Managers' and Organizational Commitment of Staff Nurses" and revealed from their study that near the half of staff nurses had moderate level regarding affective commitment. While Ali, et al., (2020) have no agreement with current study results in which they mention 
that more than two third had high level regarding continuance commitment and normative commitment.

These results come in the line with Elzohairy, et al., (2019) who studied "Relationship between Organizational Commitment and Intention to Leave among Professional Nurses at Damanhur National Medical Institute" and reported that, nearly two thirds of professional nurses had moderate level of affective commitment and less than two third of them had moderate level of affective commitment. Pertaining to continuance commitment, about two thirds of professional nurses had moderate level of continuance commitment.

Also, the study results showed that near one quarter of staff nurses had high levels for continuance commitment and normative commitment, while low percent had high level for affective commitment. This is not concurrent with Alammar, et al. (2016) results in which the coefficients were the highest for the affective commitment and this implying that affective commitment is the strongest predictor in their study.

Concerning total organizational commitment, the majority of staff nurses had moderate level of total organizational commitment; while low percent of them had low level of total organizational commitment. It might be attributed that professional nurses feel they are a part of the organization due to their participation in decision making; they had more opportunities to deal with supervisor directly, a clear channel of communications at hospital, and more years of experiences; as well as they are emotionally attached to their organization.

This result is confirmed with Hakami, et al, (2020) who studied "The Relationship between Nurses Job Satisfaction and Organizational Commitment" and reported that the majority of the staff nurses had moderate level of organizational commitment. Also, this congruent with Elzohairy, et al., (2019) who mentioned from their results that nearly two thirds of professional nurses got moderate level of organizational commitment. Also, this result is in line with Kalil et al., (2019) who portrayed that more than three fifth of staff nurses (63.3\%) had moderate level of organizational commitment; which was a good score and indicated that nurses were committed to their hospital and the profession.

In addition these results are inconsistent with Dorgham (2012) who found that the studied participants had low commitment toward their hospital, as they did not feel emotionally attached to their hospital or they felt that the hospital did not deserve their loyalty.

However, Ali, et al., (2020) have no agreement with current study finding regarding total score of organizational commitment as; they reported that more than half of staff nurses had high level commitment, and more than one third had moderate level. This mean that the staff nurses had moderate to high level of organizational commitment. Also, Lorber and Savic (2014) who have a study in Slovenian hospitals mentioned that the staff nurses level of commitment among was high to medium.

In addition these results were inconsistent with Dorgham (2012) who found that the studied participants had low commitment toward their hospital, as they did not feel emotionally attached to their hospital or they felt that the hospital did not deserve their loyalty.

Regarding the correlations matrix between the quality of nursing work life of staff nurses' and their organizational commitment, the present study showed that there were positive fair associations between total organizational commitment of the nurse's staff and their work life, work design, work context, work world, and total quality of nursing work life. Also, there were positive fair association between total quality of nursing work life of them and their continuance and normative commitment.

This result come in accordance with Bayoumy, (2016) who studied "Relationship Between Quality of Work Life and Nurses' Professional Commitment in Intensive Care Units at Selected University Hospitals" and reported that the correlation test indicated that the overall quality of working life satisfaction was statistically significant and positively correlated with professional commitment $(\mathrm{r}=$ $0.38, \mathrm{p}=0.001)$. All the quality of working life subscales was statistically significant and positively correlated with professional commitment.

\section{Conclusion}

It can be concluded from the current study that, more than half of staff nurses have moderate level regarding total scores of quality of nursing work life; and the remaining have a high level to the total quality of nursing work life. Concerning total organizational commitment, most staff nurses had a moderate level of total scores of organizational commitment. Moreover, there were positive associations between total organizational commitment of the nurse's staff and their work life, work design, work context, work world, and total quality of nursing work life. Since the higher quality of work life brings more commitment for employees'; managers can improve the essential components of working life quality of nurses by adopting appropriate solutions and providing the necessary conditions for improving the qualityof-service provision and productivity to enhance organizational commitment.

\section{Recommendations}

Based on the findings of the current study, the following recommendations are made.

1- Increase nurses' satisfaction through competitive salaries, encourage the teamwork spirit and conduct periodical meetings to discuss their problems.

2- Carry out frequent meetings with nurses who are dissatisfied from their job; discuss their problems and their needs and try to make plans to overcome these problems to improve their satisfaction level which can consequently raise their self-esteem and commitment level.

3- Hospitals managers should work with the media to demonstrate the vital role of nurses in the care of the community, in the provision of health care services and in the advancement of the health of the population.

4- Nurses should discuss their problems and their needs with the administrators to overcome these problems to enhance their quality of work life acceptance level which can consequently raise their organizational commitment level.

\section{References}

(1) Ahmed, R.M., Abdelwahab, E.A., Elguindy, H. (2017). Staff nurses' intention to leave nursing profession and their organizational commitment in selected hospitals at BeniSueif city. Egyptian Nursing Journal, 14:17-24

(2) Akter, N., Akkadechanunt, T., Chontawan, R., \& Klunklin, A. (2018). Factors predicting quality of work life among nurses in tertiary level hospitals, Bangladesh. International nursing review, 65(2), 182-189.

Mohmmed A., et al 
(3) Alammar K, Alamrani M, Alqahtani S, Ahmad M. (2016). Organizational Commitment and Nurses' Characteristics as Predictors of Job Involvement. Nursing Leadership; 29 (4): 59-69.

(4) Ali, H.A, Safan, S.M. \& Mabrouk, S.M. (2019). The work design and its Relation to Productivity among Staff Nurses. MNJ Menoufia Nursing Journal; 4(2): 83-93.

(5) Ali, H.M., Abood, S.A. \& Thabet, M. (2020). Relation between Leadership Styles and Behaviors of Nurse Managers' and Organizational Commitment of Staff Nurses. Minia Scientific Nursing Journal; 7(1); 54-62.

(6) Bayoumy S. A., \& Abdrbo A. A. (2016). Relationship Between Quality of Work Life and Nurses' Professional Commitment in Intensive Care Units at Selected University Hospitals. World Journal of Nursing Sciences, 2 (3): 133139

(7) Beloor, V., Nanjundeswaraswamy, S. T., Swamy, D. R. (2017). Employee Commitment and Quality of Work Life - A Literature Review. The International Journal of Indian Psychology; 4 (2): 175-188.

(8) Brooks, B. A., Anderson, M, A. (2005). Defining Quality of Nursing. Nursing Economic. 23(6): 319-326.

(9) Dorgham SR. (2012). Relationship between organization work climate and staff nurses organizational commitment. Nat Sci, 2012; 10:80-91.

(10) Elshahat, E. M., Shazly, M. M., \& Abd-Elazeem, H. (2019). Relationship between quality of work life and turnover intention among staff nurses. Egyptian Journal of Healthcare, 10(1), 178-193.

(11) Elzohairy, M.H, Elsayed, N.M., \& Ibrahim, S.A. (2019). Relationship between Organizational Commitment and Intention to Leave among Professional Nurses at Damanhur National Medical Institute. Port Said Scientific Journal of Nursing, 6(3), 163-177.

(12) Farokhzadian, J., Nayeri, N. D., \& Borhani, F. (2018). The long way ahead to achieve an effective patient safety culture: challenges perceived by nurses. BMC health services research, 18(1), 1-13.

(13) Hakami A, Almutairi H, Alsulyis R, Rrwis TA, Battal AA (2020) The Relationship between Nurses Job Satisfaction and Organizational Commitment. Health Sci J 14:1.

(14) Hashempour, R., Hosseinpour Ghahremanlou, H., Etemadi, S., \& Poursadeghiyan, M. (2018). The relationship between quality of work life and organizational commitment of Iranian emergency nurses. Health in Emergencies and Disasters, 4(1), 49-54.

(15) Kalil, S.I., Abd-Elrhaman, E.S. \& Sliman, W. M. (2019). Relationship among Nurses 'Locus of Control, Work Motivation Factors, and Their Organizational Commitment. American Journal of Nursing Research, 7(2): 167-178.

(16) Kowitlawkul, Y., Yap, S., Makabe, S., Chan, S., Takagai, J., Tam, W., \& Nurumal, M. (2019). Investigating nurses' quality of life and work $\square$ life balance statuses in Singapore. International nursing review, 66(1), 61-69 .
(17) Lateef, S.F., Mohamed, F.R. \& Hossny, E.K. (2021). The Relationship between Quality of Work Life, Psycho-Social Safety Climate and Nursing Staff Work Engagement and Organizational Commitment. Assiut Scientific Nursing Journal; 9(24):18-29.

(18) Lee, Y. W., Dai, Y. T., Park, C. G., \& McCreary, L. L. (2013). Predicting quality of work life on nurses' intention to leave. Journal of Nursing Scholarship, 45(2), 160-168 .

(19) Liu, W., Zhao, S., Shi, L., Zhang, Z., Liu, X., Li, L., ... \& $\mathrm{Ni}$, X. (2018). Workplace violence, job satisfaction, burnout, perceived organisational support and their effects on turnover intention among Chinese nurses in tertiary hospitals: a cross-sectional study. BMJ open, 8(6).

(20) Lorber M, Savic B. (2014). Factors affecting nurses' organizational commitment in Slovenian hospitals. Obzor Zdrav Neg, 48:294-301.

(21) Meyer JP, Allen NJ, Smith CA. (1993). Commitment to organizations and occupations: extension and test of a three-component conceptualization. J Appl Psychol. 78:538-51.

(22) Moradi T., Maghaminejad, F. \& Azizi-Fini, I. (2014). Quality of Working Life of Nurses and its Related Factors. Nurs Midwifery Stud; 3(2): e19450.

(23) Morsy, S. M., \& Sabra, H. E. (2015). Relation between quality of work life and nurses job satisfaction at Assiut university hospitals. Al-Azhar Assiut Medical Journal, 13(1), 163-171 .

(24) Nayeri, N.D, Salehi, T., \& Asadi, A.A. (2011). Quality of work life and productivity among Iranian nurses. Contemporary nurse, 39(1), 106-118.

(25) Ong, J. F. B., Tan, J. M. T., Villareal, R. F. C., \& Chiu, J. L. (2019). Impact of Quality Work Life and Prosocial Motivation on the Organizational Commitment and Turnover Intent of Public Health Practitioners. Review of Integrative Business and Economics Research, 8, 24-43 .

(26) Osemeke, M. (2016). Identification of determinants of organizational commitment and employee job satisfaction. African Research Review, 10(2), 81-102.

(27) Pio, R. J., \& Tampi, J. R. E. (2018). The influence of spiritual leadership on quality of work life, job satisfaction and organizational citizenship behavior. International Journal of Law and Management, 60 (2), 757-767

(28) Ramdhani, A., Ramdhani ‘M. A., \& Ainissyifa, H. (2017). Conceptual framework of corporate culture influenced on employees commitment to organization. International Business Management, 11(3), 826-830 .

(29) Akram, S.S \& Awad, Y. M. (2020). Advantage and limitation of nursing students' training at governmental intensive care units in Gaza strip: Nurses' perceptions. International Journal of Advance Research in Medical Surgical Nursing 2020; 2(1): 23-29

(30) Shazly, M., \& Fakhry, S. (2014). Nurses' perception of the quality of nursing work life and related priorities for improvement in Ain Shams University specialized hospital. Journal of American Science, 10(1), 123-131 